\title{
Thermo-Mechanical Analysis of Solid Interfaces in HVAC Cable Joints
}

\author{
M. A. Hamdan, J. A. Pilgrim and P. L. Lewin \\ The Tony Davies High Voltage Laboratory \\ School of Electronics and Computer Science \\ University of Southampton \\ Southampton, SO17 1BJ, UK
}

\begin{abstract}
Mechanical stresses affect the electrical performance of solid-solid interfaces in highvoltage cable joints. This paper assesses the influence of insulation material mechanical properties and temperature on interface pressure. Based on a hyper-elastic model, the mechanical stresses inside silicone rubber joint tube were determined. Circumferential stresses can reach $50 \%$ of the silicone rubber tensile strength at normal pre-operation expansion ratios. An analytical method to determine the thermally induced mechanical stress during operation is presented and its accuracy is confirmed using finite element method. This method is modified to account for the variation of the mechanical properties with temperature. This paper shows that circumferential stresses at the interface increase as temperature drops, which may have a significant impact on the electrical performance of the interface during operation.
\end{abstract}

Index Terms - cable joint, interface pressure, elastic modulus

\section{INTRODUCTION}

POWER cables are an indispensable part of the transmission and distribution infrastructure. Since the introduction of polymeric insulated medium voltage cables in 1960, significant developments and improvements have been made in the cable design. Cable accessories are still considered as the most vulnerable point in the cable system due to interfaces being formed between two different insulation materials. Interfaces are the weakest region in a cable accessory but at the same time cannot be avoided [1]

Failures among 110 and $220 \mathrm{kV}$ silicone rubber pre-moulded cable joints have been reported, for example by [2] where it was proposed that high mechanical forces could trigger the initiation and propagation of electrical trees. Microscopic cavities at the interface may be developed by mechanical forces, leading to partial discharge initiation and finally to insulation breakdown [2]. High radial pressure at the interface is desirable to reduce the size of any microscopic voids. But, if the circumferential (also known as hoop) stress is close to the tensile strength of the insulation, micro-cracks can be developed. If one of the insulation materials at the interface is too stiff (i.e. high elastic modulus) and it is expanded above a certain limit, this will impose high tensile stresses on the interface. Moreover, cable joints sometimes operate in locations that experience extremely low temperatures, which can cause insulation materials to become brittle and less flexible. In IEEE standard 404 for extruded and laminated dielectric shielded cable joints rated 2.5 to $500 \mathrm{kV}$, no correlation is found between mechanical properties of the insulation and interfacial pressure.

Manuscript received on 4 March 2019, in final form 26 June 2019, accepted xx Month 20yy. Corresponding author: M. Hamdan.
The correlation between material properties and interface pressure is a necessity to assure mutual compatibility and longterm performance after installation. Furthermore, the existing algorithms that estimate the interface pressure and its changes rarely correlate the mechanical properties of insulation materials and the mechanical stress they experience. This paper presents a calculation of the pre-operation mechanical stresses based on hyper-elastic material models, before proposing a method to calculate the thermally induced stresses (radial and hoop) at the interface during operation. This framework accounts for the changes in the elastic modulus and thermal expansion of the insulating materials. This analysis will enrich cable joint designers' ability to optimize the mechanical design of interfaces in cable accessories.

\section{WHY INTERFACE PRESSURE IS IMPORTANT}

\subsection{INTERFACE PRESSURE AND ELECTRICAL BREAKDOWN STRENGTH}

At the interface the electric field has two components, normal and parallel to the interface. The parallel or tangential component is the most critical component; although, it is much lower than the dielectric strength of the bulk insulation, defects at the interface (such as micro-cracks, cavities and contaminations) enhance the local electrical field [1]. This enhancement can lead to electrical treeing and partial discharge initiation. Mechanical conditions also affect the electrical breakdown strength, which has been shown to improve 
significantly in the presence of a softer material (lower Young's modulus) while increasing the applied pressure. This enhancement in the breakdown strength was explained by the fact that any voids formed will be smaller when a softer material is used and subject to a higher pressure [3]. It is known that electrical tree propagation is affected by mechanical stresses. In [4] it was concluded that the propagation of electrical trees is influenced by tensile and compressive stresses. In addition, it was noted that the treeing process is accelerated by higher tensile stress. On the other hand, the tree growth is reduced by compressive stresses. The compressive stress increases the cohesion strength and therefore restrains the propagation of electrical trees. Accordingly, studying the interface pressure and its effects on the electrical strength is important to optimise these interfaces.

When it comes to the design and the testing of cable joints there is no solid agreement on the required interface pressure even in the same range of voltage [5]. Designers have different minimum interfacial pressure depending on voltage level, materials used and joint type, leading to variation in the minimum radial interfacial pressure from 0.08 up to $1 \mathrm{MPa}$ [5]. Assuring enough radial interfacial pressure is vital. However, if the hoop stresses are above or near to the tensile strength of material, cracks may develop at the interface.

\subsection{INFLUENCES ON INTERFACE PRESSURE}

Several factors could influence cable joint interface pressure, including; residual stress in cable insulation, relief of elasticity of rubber, temperature, thermo-mechanical forces, mechanical properties of materials. Residual stresses develop during manufacturing as the cable insulation cools and influence both mechanical and electrical properties of the cable. During cable installation or maintenance, they pose a challenge for cable joints because the insulation tends to shrink back in the axial direction on the conductor. However, in [6] it was found that there is no significant influence of residual mechanical stresses on insulation breakdown strength, tree inception voltage and tree propagation rate. Moreover, the residual stress in the radial direction is compressive and has no impact on the strength of the cable because it is aligned in the electrical field direction. Residual stresses in the angular direction were measured for cables between 132 and $400 \mathrm{kV}$ and it was concluded their values were low to cause any impact on cable performance [7].

To maintain the necessary interface pressure between joint tube and cable insulation, a joint tube with high elastic modulus is used. During long-term use, relief of elasticity of rubber can occur. Therefore, critical low interface pressure should be prevented by making sure that the rubber will stabilize at a safe value. However, there are no reports about failures due to relief of elasticity of rubber [8]. For pre operation, stress relaxation of rubber depends mainly on storage conditions (time and temperature). Stress decay in rubber is very slow and it may take several weeks to relax and stabilize [9].

Polymers have a viscoelastic behavior, where the material exhibit both viscous and elastic characteristics. However, the degree of viscoelasticity is highly dependent on temperature, rate of deformation, degree of crystallinity, crosslinking and molecular mass of the polymer. The stress levels generated due to expansion and contraction of insulation are lower than stresses developed during manufacturing. Considering XLPE as elastic can be enough to explain such low strains from thermal expansion. Relaxation tests on XLPE have revealed that there are short and long-term relaxation processes. These relaxation processes are turned off as temperature increases. Moreover, temperature increase did not change the relaxation time [10]. Furthermore, there is no evidence of instability in interface pressure during thermal cycling that could be caused by stress relaxation of XLPE [11].

The mechanical properties of the materials such as elastic modulus, thermal expansion, hardness, and tensile strength limits affect the interface breakdown strength. The reliability of the interface is dependent on the right combination of insulation materials and their properties. However, mechanical properties of insulation materials and their effect on the stresses at the interface need more attention. In the following section, the influence of insulation mechanical properties on interface pressure is highlighted.

\section{INTERFACE PRESSURE AND INSULATION MECHANICAL PROPERTIES}

Silicone rubber joint tubes are responsible for establishing the initial interface pressure. Three main parameters control the magnitude of this interface pressure: elastic modulus, strain (expansion ratio) and wall thickness of the rubber [1]. Materials with high elastic modulus need low expansion ratio to achieve the pressure needed and vice versa. The maximum expansion ratio is limited by the materials elongation at break. Modern pre-moulded cable joints often use the cold shrink technique, where the pre-moulded joint body will be pre-expanded with larger expansion ratio and placed on a support tube in order to be placed around the cable in the right position. Then, by removing the support tube, the joint body shrinks by its own elasticity [12]. The pre-expanding expansion rate is higher than $50 \%$. On the other hand, the operation expansion rate is the difference between the outer diameter of cable insulation and the inner diameter of the joint tube which is normally smaller than the outer diameter of the cable. This expansion rate is recommended to be in the range of 5 to $50 \%$ [1].

Semi conductive stress cones, which are part of joint tube, are often made of rubber loaded with carbon black filler, and this makes it stiffer than unfilled material [13]. It was proposed that if the semi-conductive (semi-con) material is too stiff and it was expanded, high circumferential stress could be established at the interface between the semi-con screen and joint insulation. These high stresses in the joint tube could explain electrical breakdown in the failed joints in [2]. In the following sub sections, the methods found in the literature to determine the interface pressure are presented. Finally, the aim of this work is summarized.

\subsection{METHODS USED TO CALCULATE INTERFACE PRESSURE}

To estimate the initial interface pressure, linear and nonlinear material models are used to model joint tube behaviour [5, 14]. 
In linear material models, the stress-strain relation of materials is linear indicating that the Young's modulus is assumed to be constant. However, for pre-operation conditions the deformations the joint tube experiences more than $50 \%$. For large deformations the elastic behavior of rubber can no longer be explained by a simple constant elastic modulus [13], instead requiring a nonlinear elastic relationship. To be able to calculate interface pressure accurately, the elastic modulus of rubber should be determined. Rubber is a non-linear elastic material so stresses cannot be described as a linear function of strains; instead, laws for hyper-elastic materials are commonly used. The authors in [14] modeled the stress-strain relation for silicone rubber and semi-con layers by a hyper-elastic model. However, the material model used is only reliable and sufficient for material strain up to $30 \%$ and the joint tube stain can reach $50 \%$. Other studies measure interface pressure experimentally using pressure sensors; however, this could damage the interface and affect the reliability of the readings.

In order to evaluate the change in interface pressure due to thermal cycling and temperature change, a model was proposed in [11], which found that the effect of thermal cycling on the interfacial pressure depends on the insulation material. However, the temperature in each material was supposed to decrease linearly with radius leading to deviation from the real situation. In addition, the model did not consider the variations of the materials moduli of elasticity and thermal expansion coefficients with temperature. Figure $1 \mathrm{a}$ and $1 \mathrm{~b}$ shows the elastic modulus and thermal expansion as a function of temperature for both XLPE and silicone rubber.
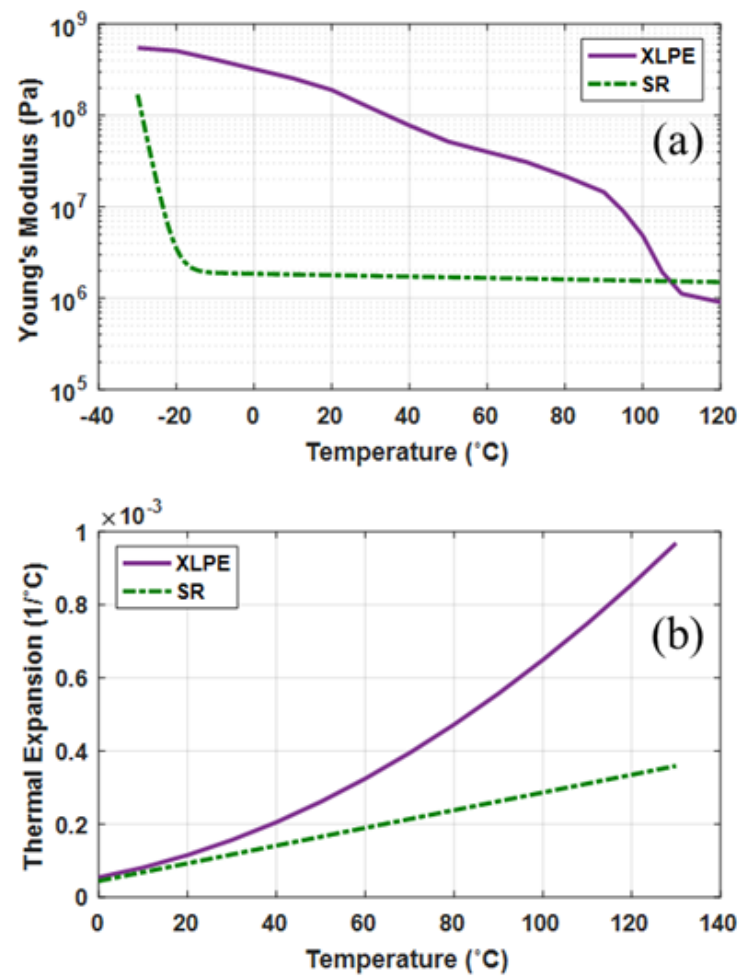

Figure 1. (a) Elastic modulus of the cable and joint insulation [5, 15]; (b) thermal expansion of cable and joint insulation [16, 13].

The insulation resistance to deformation depends on the operating temperature, which will vary during the life of a cable joint. The elastic modulus of insulation material is temperature dependent, and the decrease in elastic modulus seen at high temperature could also affect the interface. Moreover, rubber and rubber like materials (elastomers) have a coefficient of thermal expansion in a range of $2.5 \times 10^{-4}-4.8 \times 10^{-4} \mathrm{~K}^{-1}$, which is a tenfold difference when compared to copper thermal expansion as an example $1.9 \times 10^{-5} \mathrm{~K}^{-1}$ [13]. The high thermal expansion coefficient of rubber indicates that thermally induced stress in the rubber could be high, especially when rubber is restricted and subsequently heated.

\subsection{AIM OF THIS WORK}

The work done in this paper can be divided in two parts. The first part deals with the mechanical stresses inside the joint tube alone. The second part handles the thermal stresses inside the cable joint during operation.

In section four, the mechanical stresses inside the joint tube are calculated based on a hyper-elastic model using the finite element method. The aim of this calculation is to find the circumferential stress and to check if it exceeds the strength of the joint tube over the entire range of expansion ratio. In section five, an analytical model for thermal stresses inside cable joints is developed to determine the changes in interface pressure.

\section{MECHANICAL STRESS IN JOINT TUBE}

In this part, stresses for three silicone rubber materials each having different elastic modulus are explored. Then one of the silicone rubber materials is simulated with three semiconductive materials each having different elasticity. The joint tube is modeled as a cylinder under internal pressure. A cross section of the joint body with the central semi-con and a cross section of joint insulation body alone are analyzed. The joint tube and semi-con materials are considered as silicone rubber and rubber reinforced by carbon black filler, respectively.

\subsection{HYPER-ELASTIC MATERIAL IN FINITE ELEMENT}

Hyper-elastic materials are characterized by a strain energy function, which describes the potential energy stored due to a given deformation. Strain energy functions are represented in terms of stretch ratios $\lambda$ or indirectly in terms of strain invariants I. Stretch ratio is defined as the ratio of the deformed length divided by the original length. Strain invariants are the measures of strain which are independent of the coordinate system [17]. For hyper-elastic materials, a second term is added to account for compressibility. In this work, the material is considered as nearly incompressible with a Poisson's ratio between $0.49-0.5$ to avoid any numerical errors. The bulk modulus $k \mathrm{GPa}$, also known as modulus of compressibility, is defined as the ratio of the pressure required for a unit relative decrease in volume. Neo Hookean, Mooney Rivlin, Yeoh and Ogden are examples of hyper-elastic material models that can be used to represent the stress-strain relationship. Each model covers a certain strain range. Using finite element method, Yeoh and Ogden functions are adopted for semi-con and joint insulation respectively. The hyper-elastic models used for this purpose were chosen to be sufficient for a strain more than $100 \%$ [18]. To describe stress-strain relation of carbon-black filled rubber, Yeoh model is suitable $[17,18]$. The general form 
of Ogden and Yeoh model are described respectively as [17, 18]:

$$
\begin{gathered}
W=\sum_{n=1}^{N} \frac{\mu_{n}}{\alpha_{n}}\left(\lambda_{1}^{\alpha_{n}}+\lambda_{2}^{\alpha_{n}}+\lambda_{3}^{\alpha_{n}}-3\right)+\frac{1}{2} k\left(J_{e l}-1\right)^{2} \\
W=\sum_{i=1}^{N} C_{i 0}\left(\bar{I}_{1}-3\right)^{i}+\frac{1}{2} k\left(J_{e l}-1\right)^{2}
\end{gathered}
$$

where $W$ is the strain energy potential $\mathrm{J}^{-3} \mathrm{~m}^{-3}, \mathrm{~N}$ is the number of terms, $\mu_{n}$ is a constant $\mathrm{MPa}, \alpha_{n}$ is a dimensionless constant, $\lambda_{i}$ $(i=1,2$, and 3$)$ is known as the principle stretch in the principal directions of the deformation, $C_{i 0}$ are material constants $\mathrm{MPa}$, $I_{1}$ is the first invariant of the deviatoic strain and $J_{e l}$ is the elastic volume ratio.

\subsection{FINITE ELEMENT MODEL}

Using COMSOL multi-physics the stress profile inside the joint tube is studied at two cross sections. Taking advantage of symmetry, a $90^{\circ}$ sector is analyzed. In Figure 2, the mechanical boundary conditions are shown. Under the mechanical interface, two lines are set as symmetry $(\mathrm{n} \cdot \mathrm{u}=0)$ where; $\mathrm{n}$ is the unit vector normal to the surface and $\mathrm{u}$ is displacement in $\mathrm{mm}$. The circumference of joint insulation is defined as free. A boundary pressure $\mathrm{P} \mathrm{MPa}$ is applied at the inner radius to represent the pressure from either the cable or the support tube. The parameters for the Ogden relation are those given in Table 1. These constants are taken from [19] and [20] to represent silicone rubber in COMSOL with three different elastic modulus.
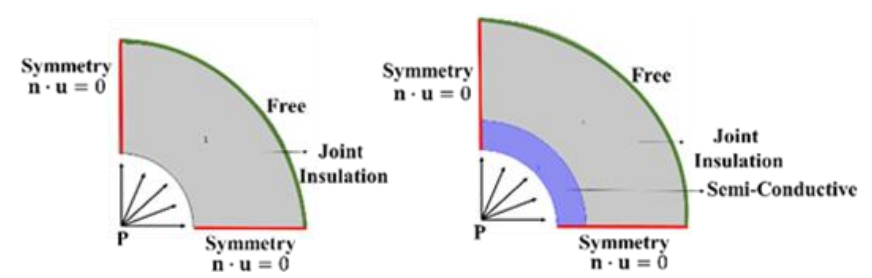

Figure 2. Quarter section of joint insulation tube without and with semiconductive material.

\begin{tabular}{|c|c|c|c|}
\hline Material & $\mathrm{N}$ & \multicolumn{2}{|c|}{$\begin{array}{l}\text { Coefficients (Ogden model) } \\
\text { Bulk modulus }(k)=2 \mathrm{GPa}\end{array}$} \\
\hline $\begin{array}{c}\text { Silicone Rubber (SR1) } \\
\text { [19] }\end{array}$ & 4 & $\begin{array}{l}\mu_{1}=0.291 \\
\mu_{2}=0.0034 \\
\mu_{3}=2.01 \mathrm{e}-11 \\
\mu_{4}=-1.15 \mathrm{e}-2\end{array}$ & $\begin{array}{l}\alpha_{1}=2.17 \\
\alpha_{2}=9.06 \\
\alpha_{3}=34.3 \\
\alpha_{4}=5.4\end{array}$ \\
\hline $\begin{array}{c}\text { Silicone Rubber (SR2) } \\
{[20]}\end{array}$ & 3 & $\begin{array}{l}\mu_{1}=0.46, \\
\mu_{2}=0.00027 \\
\mu_{3}=-0.0074\end{array}$ & $\begin{array}{l}\alpha_{1}=1.4 \\
\alpha_{2}=10 \\
\alpha_{3}=-3.3\end{array}$ \\
\hline $\begin{array}{l}\text { Silicone Rubber (SR3) } \\
{[20]^{*}}\end{array}$ & 3 & $\begin{array}{c}\mu_{1}=0.3764 \\
\mu_{2}=0.00022 \\
\mu_{3}=-0.0061\end{array}$ & $\begin{array}{l}\alpha_{1}=1.14 \\
\alpha_{2}=8.18 \\
\alpha_{3}=-2.7\end{array}$ \\
\hline
\end{tabular}

Table 1. Values of the hyper-elastic function parameters for joint insulation.

\subsection{JOINT INSULATION STRESSES}

Figure 3 shows the relation between the interfacial pressure (radial stress) and hoop stress versus expansion ratio for three different elastic relations of silicone rubber. The quarter sector of joint insulation modeled is presented next to Figure 3 and the red marker shows the measuring point.
At 50\% expansion ratio, a radial pressure of $0.200,0.165$ and $0.110 \mathrm{MPa}$ are achieved for SR1, SR2 and SR3 respectively. This implies that SR3 has the lowest elastic modulus. To obtain higher radial pressure when utilizing SR3, higher expansion ratio is needed. The materials can be arranged from the highest to lowest elastic modulus as SR1>SR2>SR3. It is noticed that the radial pressure can be increased by either increasing the elastic modulus or expansion ratio. From Figure 3b, the hoop stress at $100 \%$ expansion ratio is $3.69,1.17$ and $0.70 \mathrm{MPa}$ for SR1, SR2 and SR3, respectively. The tensile strength of silicone rubber is between 7-9 MPa [14]. Although the tensile strength is not exceeded by any of the simulated materials, the risk of approaching $50 \%$ of the tensile strength is present for SR1.
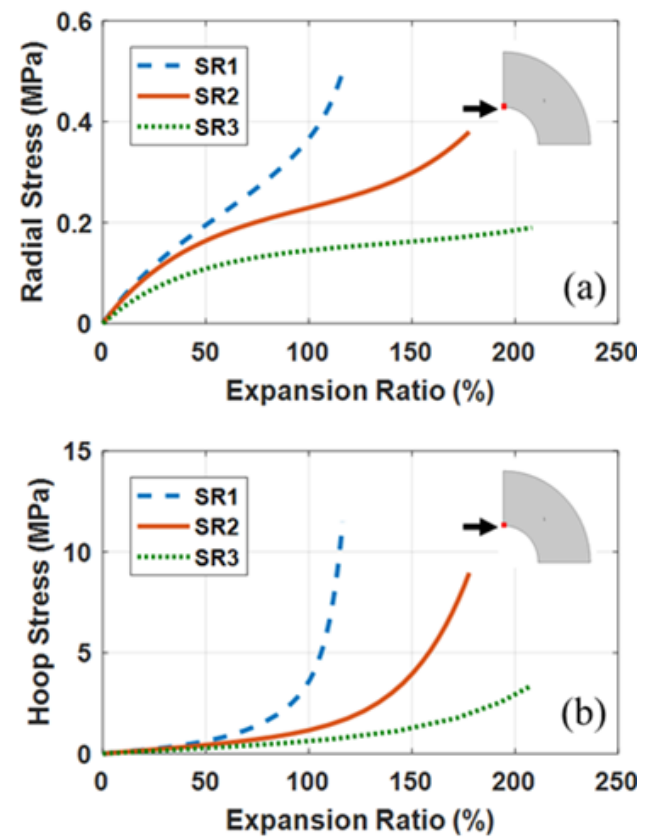

Figure 3. (a) Radial and (b) hoop stresses verses expansion ratio for three different parameters of silicone rubber of thickness $50 \mathrm{~mm}$.

\subsection{JOINT INSULATION AND SEMI-CON STRESSES}

The stresses at semi-con screen interfaces is also of interest. In Table 2, the coefficients of Yeoh model for three semi-con materials are listed.

Table 2. Parameters of Yeoh Model for Semi-con

\begin{tabular}{ccc}
\hline Material & $\mathrm{N}$ & $\begin{array}{c}\text { Material constants (Yeoh model) } \\
\text { Bulk modulus }(\mathrm{k})=2 \mathrm{GPa}\end{array}$ \\
\hline Semi-Con1 [21] & 3 & $\mathrm{C}_{10}=0.8216 \quad \mathrm{C}_{20}=0.1115 \mathrm{C}_{30}=-0.0036$ \\
\hline Semi-Con2 [21] & 3 & $\mathrm{C}_{10}=0.6278 \quad \mathrm{C}_{20}=0.0900 \mathrm{C}_{30}=-0.0023$ \\
\hline Semi-Con3 [22] & 3 & $\mathrm{C}_{10}=0.4989 \mathrm{C}_{20}=0.0347 \mathrm{C}_{30}=-2.28 \mathrm{e}-4$ \\
\hline
\end{tabular}

Figure 4 shows the radial and inner hoop stresses versus expansion ratio three different semi-con materials. As shown in Figure 4a the radial stresses obtained at 50\% expansion ratio are $0.45,0.37$ and $0.3 \mathrm{MPa}$. Generally, the radial stresses are higher than the stress obtained for SR2 alone in Figure 3a. This is expected since the semi-con is stiffer than the joint insulation. The inner hoop stresses at the interface between the joint insulation and the three semi-con materials are 2.06, 1.56 and 
$1.14 \mathrm{MPa}$ at $50 \%$ expansion ratio. Also at $100 \%$ expansion ratio, the stresses are 5.2, 3.94 and $2.75 \mathrm{MPa}$ for the three semicon materials respectively. It can be inferred that even at low expansion ratios, semi-con with high elastic modulus could introduce high hoop stresses. When a softer (lower elastic modulus) joint insulation than SR2 is used, the inner hoop stresses increase by $50 \%$. On the other hand, increasing the elastic modulus of semi-con material increased the inner hoop stress by $80 \%$. As the expansion ratio increases the risk of having stresses near the tensile strength limit increases.
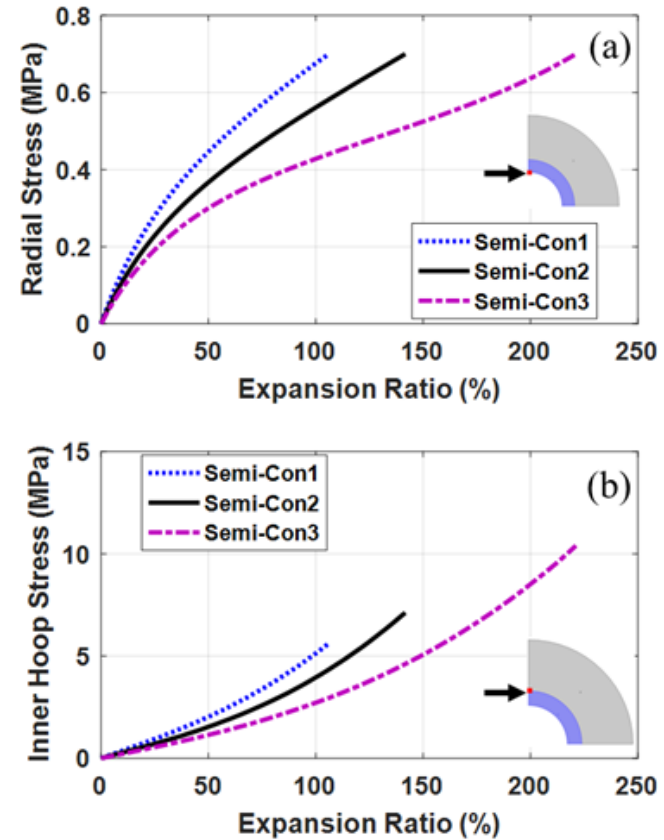

Figure 4. (a) Radial and (b) inner hoop verses expansion ratio for three semicon materials.

Achieving the highest permissible interfacial pressure by controlling the expansion ratio only without linking it to the elastic modulus is not enough to design a mechanically robust interface. Controlling the expansion ratio only may lead hoop stress to reach $50 \%$ of the tensile strength of joint insulation if the elastic modulus of material is high. Furthermore, expansion ratio above $60 \%$ and up to $150 \%$ in the pre-installation stage needs to be correlated with the elastic modulus of both materials to make sure that the hoop stresses do not exceed the critical values. When defining the value for the tensile strength of a material, a group of tests is preformed and statistical analysis is done. The outcome of this analysis produces an average value, which is used to represent the material property [23]. This implies that some samples could have a lower tensile strength, which increases the probability of reaching the lower limit of material tensile strength.

\section{THERMAL STRESSES INSIDE CABLE JOINT}

A modified thermo-mechanical model to calculate the change in interface pressure due to temperature is presented. The model accounts for the temperature dependence of elastic modulus and thermal expansion. In this part, all materials are assumed to be elastic, as for small strains the stress-strain relation could be approximated by a linear relation. It has been indicated that for a strain of 5 or $10 \%$ the error in using a linear approximation of the elastic modulus would be of 5 or $10 \%$ depending the strain value [12]. The analytical method is explained in the appendix.

\subsection{FINITE ELEMENT METHOD}

Using Finite element method, the analytical model was verified. Thermal and mechanical physical interfaces are linked to analyze this mechanical stress problem. Assuming symmetry only a quarter of the cable joint is modeled. The boundary conditions for the thermal and mechanical physics are shown in Figure 5. The thermal losses are for a $132 \mathrm{kV}$ cable joint with $630 \mathrm{~mm}^{2}$ conductor cross section area; joule and voltage dependent dielectric losses are calculated based on IEC 602871-1 and are set as heat sources. For this joint, dielectric losses were almost $3 \%$ of the joule losses. The external thermal resistance is obtained assuming the cable joint in free air. Thermal and mechanical symmetry is set at boundary 1 and 2 . Free boundary condition is considered at boundary 3 under the mechanical physics. The mathematical equation for the thermal physics is stated where $k$ is the thermal conductivity $\mathrm{W} \cdot \mathrm{m}^{-1} \cdot \mathrm{K}^{-1}$, and $Q$ is the heat source $\mathrm{W} . \mathrm{m}^{-3}$. For the mechanical physics, the equation for a deformable body is used to find the internal forces where $\sigma$ is the stress $\mathrm{Pa}$ and $F v$ is the body force per unit volume. Insulation properties and model parameters are listed in Table 3 and Table 4 respectively. The elastic modulus values of the cable and joint insulation as function of temperature were taken from [5] and [15] respectively. Thermal expansion of cable and joint insulation were taken from [16] and [13] respectively. The data for elastic modulus and thermal expansion are approximated by functions presented in the Appendix.

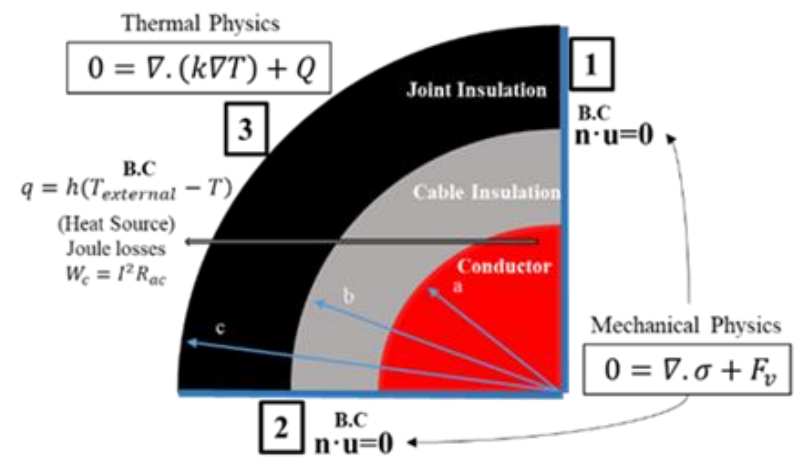

Figure 5. Illustration of model geometry and boundary setting.

Table 3. Insulation properties/

\begin{tabular}{|c|c|c|}
\hline Parameter & Cable Insulation & Joint Insulation \\
\hline Thickness & $20.25(\mathrm{~mm})$ & $49.5(\mathrm{~mm})$ \\
\hline Thermal Resistivity & $3.5\left(\mathrm{~m} . \mathrm{K}^{-1}\right)$ & $5\left(\mathrm{~m} . \mathrm{K}^{-1} \mathrm{~W}^{-1}\right)$ \\
\hline Poisson's Ratio & 0.46 & 0.49 \\
\hline $\tan \delta$ & 0.005 & 0.013 \\
\hline
\end{tabular}

Table 4. Model parameters.

\begin{tabular}{|c|c|}
\hline Parameter & Value \\
\hline Conductor Material & Copper \\
\hline Thermal Expansion $(\mathrm{Cu})$ & $1.9 \times 10^{-5}\left({ }^{\circ} \mathrm{C}^{-1}\right)$ \\
\hline Ambient Temperature & $25\left({ }^{\circ} \mathrm{C}\right)$ \\
\hline Heat Transfer Coefficient $(\mathrm{h})$ & $4.54\left(\mathrm{~W} \cdot \mathrm{m}^{-2} \cdot \mathrm{K}^{-1}\right)$ \\
\hline
\end{tabular}




\subsection{RESULTS}

Figure 6a shows the change in radial stress within the cable joint assembly in air, when the conductor temperature is at $90^{\circ} \mathrm{C}$. The difference in the interfacial pressure results obtained by FEM and analytical approaches are presented in Table 5.

Table 5. Comparison of results obtained by FEM \& analytical approaches.

\begin{tabular}{|l|c|c|c|}
\hline \multicolumn{1}{|c|}{ Approach } & FEM & Analytical & Difference \\
\hline Radial Stress & $-1.924 \times 10^{4} \mathrm{~Pa}$ & $-1.897 \times 10^{4} \mathrm{~Pa}$ & $1.5 \%$ \\
\hline Inner Hoop Stress & $1.221 \times 10^{5} \mathrm{~Pa}$ & $1.125 \times 10^{5} \mathrm{~Pa}$ & $7.8 \%$ \\
\hline
\end{tabular}

The deviation arises from the slight difference between estimated values of elastic modulus and thermal expansion. The negative value of the radial stress at the interface means that it is an increase in the initial compressive radial stress. If the initial compressive stress is $0.1 \mathrm{MPa}$ an increase of $19 \%$ in radial compressive stress is expected at $90^{\circ} \mathrm{C}$. The change in hoop stress versus radius within the cable joint assembly in air, at $90^{\circ} \mathrm{C}$ is illustrated in Figure $6 \mathrm{~b}$. The hoop stress at the interface is tensile stress. As can be seen from Figure $6 \mathrm{~b}$ the absolute maximum stress values is that reached by hoop at the inner edge.
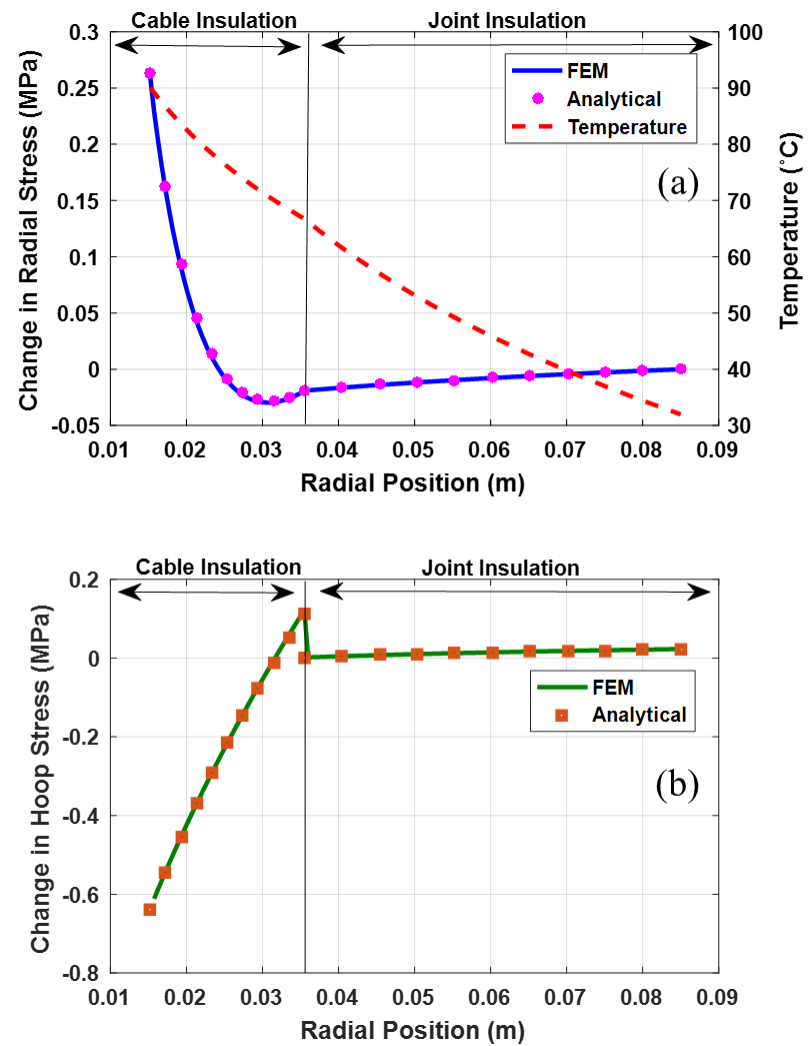

Figure 6. (a) Change in radial stress within the cable joint at $90^{\circ} \mathrm{C}$; (b) change in inner hoop stress within the cable joint at $90{ }^{\circ} \mathrm{C}$.

\subsection{SENSITIVITY ANALYSIS}

A sensitivity analysis was conducted on the model to investigate the effect of the mechanical properties (e.g. Elastic modulus and thermal expansion) on the change of the radial and inner hoop stress. The elastic modulus and thermal expansion of cable and joint insulation $E_{c}, \alpha_{c}, E_{j}$ and $\alpha_{j}$ respectively with their interactions have been examined. The change in the elastic modulus of the joint insulation and thermal expansion of the cable insulation have the highest effects on the interface pressure as shown in Figure 7a. The elastic modulus $\mathrm{E}_{\mathrm{c}}$ has the lowest impact of 0.061 . The main parameters that affect the change of the inner hoop stress are presented in Figure $7 \mathrm{~b}$. The influence of cable insulation properties is higher than in the radial pressure especially the effect of $E_{c}$ which has increased from 0.061 to 13.232. Unlike radial pressure, the joint insulation elastic modulus and cable insulation thermal expansion have negative impact on change of inner hoop stress. Based on this study, the elastic modulus of joint insulation has the highest effect on thermally induced stresses.
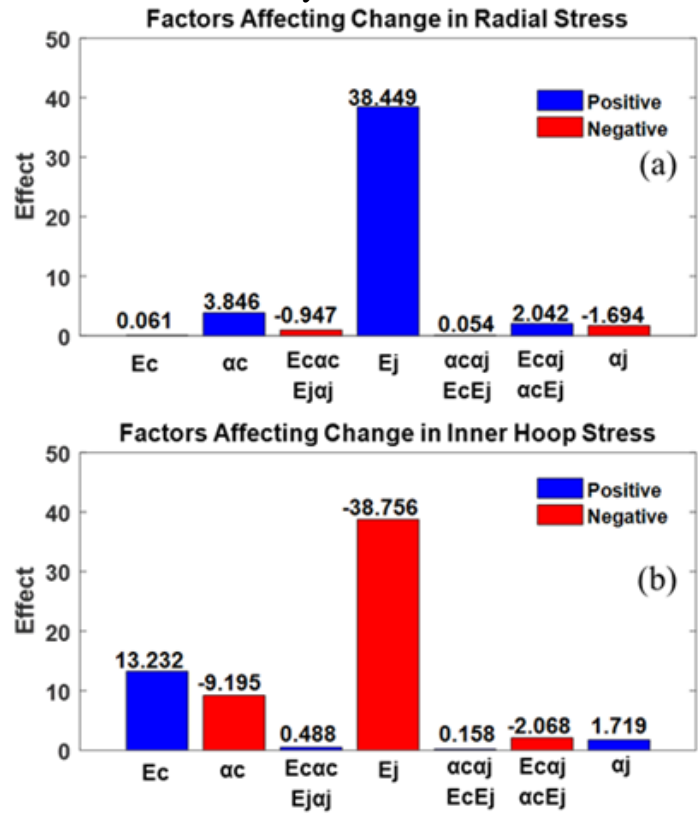

Figure 7. Main and interaction effects of thermal expansion and elastic modulus of insulation materials at conductor temperature of $90{ }^{\circ} \mathrm{C}$.

\subsection{HIGH AND LOW TEMPERATURE IMPACT}

The change in compressive radial stress due to different currents and interface temperature is illustrated in Figure 8a. No reduction in the initial radial compressive stress is observed since all values are compressive. At input current of 1297 A, this enhancement in the initial compressive stress increases from -0.019 to $-0.025 \mathrm{MPa}$ as interface temperature goes up from 24 to $86.5^{\circ} \mathrm{C}$. A slight decrease in this stress is observed when the interface temperature is near the critical temperature for cable insulation at $109{ }^{\circ} \mathrm{C}$ where the elastic modulus drops. Nevertheless, in normal operation interface temperature does not exceed $70{ }^{\circ} \mathrm{C}$ so no drop in interface pressure is expected. At input current of 897 A the change in radial stress is decreased as temperature decreases until it reaches $-20^{\circ} \mathrm{C}$. The increase in the elastic modulus of the joint insulation at low temperature justifies the increase from -0.0047 to $-0.0054 \mathrm{MPa}$ when the interface temperature goes from -10 to $-20^{\circ} \mathrm{C}$.

In Figure $8 \mathrm{~b}$ the change in the inner hoop stress caused by different input current and interface temperatures is presented. At high interface temperature the amount of change in the inner hoop stress is low. At 1297 A the change in inner hoop drops from 0.481 to $0.035 \mathrm{MPa}$ as temperature increases from 23 to $109{ }^{\circ} \mathrm{C}$. The change in the elastic modulus of the joint insulation in the same temperature range is not significant at $17 \%$. The 
inner hoop stress is more affected by properties of the cable insulation. The change in elastic modulus of the cable insulation in the same temperature range is more than $90 \%$. When temperature starts to decrease the inner hoop stress enhances the initial tensile inner hoop up to a certain limit. This enhancement is driven by the increase in the elastic modulus of the cable insulation. The sudden increase in the elastic modulus of the joint insulation is considered as a turning point for the change in inner hoop stress since it starts decreasing as seen in Figure $8 b$.
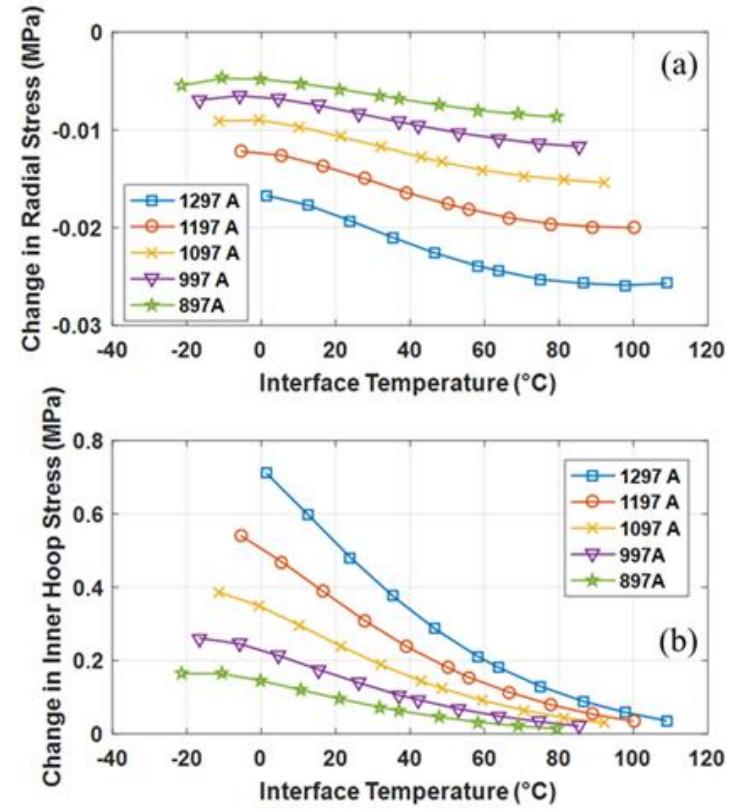

Figure 8. Change in (a) radial stress and (b) inner hoop stress with changing current and interface temperature.

Based on this, the initial radial compressive stress is expected to increase but the extent of this increase will depend on temperature and material properties. The initial inner hoop stress is expected to increase as interface temperature drops, which could be more critical if the initial value is already high close to the tensile strength limit. Tensile stress promotes yielding and compressive stress delays yielding so if any defect is present at the interface, thermally induced stresses could make the condition worse. The elastic modulus of the joint insulation has the largest effect on thermally induced stresses. However, the change in the elastic modulus of joint insulation due to temperature is minor. The influence of cable insulation properties is lower than the joint insulation but at the same time, it changes with temperature significantly. Therefore, the effect of cable insulation properties should not be ignored when dealing with thermally induced stresses.

\section{CONCLUSIONS}

At the interface of two insulation materials, mechanical pressure and electrical performance are closely related with each other. This paper has presented a thermo-mechanical analysis for solid-solid interfaces in HV cable joints. The initial stresses inside joint tube have been calculated. Limiting the expansion ratio only is not sufficient to assure a mechanically stable interface. High initial circumferential (hoop) stress could result due to utilizing materials with high Young's modulus even within the permissible limit of expansion ratio, especially at the interface of the semi-con layer and the joint insulation. Stiffer semi-con layer were found to increase the inner hoop stresses by $80 \%$.

A method for the calculation of thermally induced stresses has been proposed. This framework presents an improvement in existing algorithms for estimating the change in interface pressure, since it accounts for the variations in temperature dependent properties of the insulating materials. At conductor temperature of $90^{\circ} \mathrm{C}$, it is noticed that both the initial compressive radial and tensile inner hoop are increased due to temperature increase. The elastic modulus of joint insulation has the largest effect on thermally induced stresses. However, the change in cable insulation material properties with temperature is higher which affects the interface pressure. Furthermore, at low temperature the inner hoop stresses could increase the risk of having problems at the interface.

\section{APPENDIX \\ ANALYTICAL MODEL}

The cable joint is modelled as a thick wall cylinder where the ratio of wall thickness $s$ and the inside diameter $d_{i}$ is higher than 0.05 [24]. Plane strain state equations are considered where the cylinder is either constrained at the ends or infinitely extended along the axis. When analyzing thick wall cylinders, stress, strain and displacement are considered as functions of radial coordinate $r$, irrelevant to the tangential coordinate $\theta$. By ignoring the tangential coordinate $\theta$, the tangential (hoop) stress $\sigma_{\theta}$ and radial stress $\sigma_{r}$ are functions of the radial coordinate $r$ [24]. The differential equation that describes the model in radial direction can be written in terms of the displacement $u$ as [24]:

$$
\begin{gathered}
u^{\prime \prime}+\frac{u^{\prime}}{r}-\frac{u}{r^{2}}+\frac{E^{\prime}(r)}{E(r)}\left(u^{\prime}+\frac{v}{1-v} \frac{u}{r}\right)=\frac{1+v}{1-v} \\
\left.\alpha(r) T^{\prime}(r)+T(r) \alpha^{\prime}(r)+\alpha(r) T(r) \frac{E^{\prime}(r)}{E(r)}\right]
\end{gathered}
$$

where $\alpha, E$ and $v$ are the thermal expansion coefficient ${ }^{\circ} \mathrm{C}^{-1}$, Young modulus $\mathrm{MPa}$ and Poisson's ratio respectively. The steady state temperature distribution $T^{\circ} \mathrm{C}$ inside each layer of the cable joint in Figure 6 can be computed using the following equation, assuming the internal and external radii of the layer to be $\mathrm{a}$ and $\mathrm{b}$ respectively:

$$
T(r)=\frac{T_{1}-T_{2}}{\ln \frac{a}{b}} \ln \frac{r}{b}+T_{2}
$$

The elastic modulus $E_{a}$ and $E_{b}$ at the inner and outer radius $\mathrm{a}, \mathrm{b}$ in Figure 5 are determined based on equation $5 \mathrm{a}$ where $\mathrm{T}$ is temperature ${ }^{\circ} \mathrm{C}$ and $\mathrm{A}, \mathrm{B}, \mathrm{A}_{1}, \mathrm{~B}_{1}$, and $\mathrm{C}_{1}$ are fitting constants. Using the curve fitting the elastic modulus and thermal expansion of each material were expressed as functions in terms of temperature. The variation of the elastic modulus within the material is calculated based on these values and the constants $m_{1}$ and $m_{2}$, which are determined by Equation 6a, the thermal expansion, is presented by a similar approach. The functions 
used to approximate material properties in Figure 2 are presented in Table A1.

$$
\begin{gathered}
E(T)=A e^{B T} \\
\alpha(T)=A_{1} T^{2}+B_{1} T+C_{1} \\
E(r)=E_{a}\left(\frac{r}{a}\right)^{m_{1}} \text { where } m_{1}=\frac{\ln \left(\frac{E_{a}}{E_{b}}\right)}{\ln \left(\frac{a}{b}\right)} \\
\alpha(r)=\alpha_{a}\left(\frac{r}{a}\right)^{m_{2}} \text { where } m_{2}=\frac{\ln \left(\frac{\alpha_{a}}{\alpha_{b}}\right)}{\ln \left(\frac{a}{b}\right)}
\end{gathered}
$$

Table A1. Fitting constants used in analytical model.

\begin{tabular}{cc}
\hline Elastic & $E_{\text {Cable }}(T)=3.8 \times 10^{8} e^{-0.038 T}$ \\
modulus & $E_{\text {Joint }}(T)=3.6 \times 10^{6} e^{-0.01713 T}$ \\
\hline Thermal & $\alpha_{\text {Cable }}(T)=3.6 \times 10^{-8} T^{2}+2.3 \times 10^{-6} T+7.4 \times 10^{-5}$ \\
expansion & $\alpha_{\text {Joint }}(T)=2.4 \times 10^{-6} T+8.9 \times 10^{-5}$ \\
\hline
\end{tabular}

If the elastic modulus and thermal expansion are presented as power law functions, the second order differential equation takes the form of Euler-Chauchy differential equation with constant coefficients and the complete solution for $u$ can be written as:

$$
u(r)=u_{g}(r)+u_{p}(r)=F_{1} r^{\beta_{1}}+F_{2} r^{\beta_{2}}+u_{p}(r)
$$

where $u_{g}(r)$ is the general solution and $u_{p}(r)$ is the particular solution. $\beta_{1}$ and $\beta_{2}$ are the roots of the characteristic equation and $F_{1}$ and $F_{2}$ are constants which can be determined by applying the boundary conditions. The boundary conditions for this problem as seen in Figure 5 are given by [11]:

$$
\begin{gathered}
u_{\text {cable }}(a)=a \alpha_{c} \Delta T, \quad u_{\text {cable }}(b)=u_{\text {joint }}(b) \\
\sigma_{\text {cable }}(b)=\sigma_{\text {joint }}(b), \quad \sigma_{\text {joint }}(c)=0
\end{gathered}
$$

where $\mathrm{a}, \mathrm{b}$ and $\mathrm{c}$ are radius of the conductor, cable insulation and joint insulation respectively. The linear thermal expansion of the conductor is presented by $\alpha_{c} . u$ and $\sigma$ are the displacement and stress function of the materials. Once the displacement $u$ is determined, the radial and hoop stresses can be presented by:

$$
\begin{gathered}
\sigma_{r}=\frac{E(1-v) u^{\prime}}{(1-2 v)(1+v)}+\frac{E v(1-v) u}{(1-2 v)(1+v) r}-\frac{E \alpha \Delta T}{1-2 v} \\
\sigma_{\theta}=\frac{E v u^{\prime}}{(1-2 v)(1+v)}+\frac{E(1-v) u}{(1-2 v)(1+v) r}-\frac{E \alpha \Delta T}{1-2 v}
\end{gathered}
$$

\section{REFERENCES}

[1] Cigre, "Interfaces In Accessories for Extruded HV and EHV Cables," Joint Task Force 21/15, 2002.

[2] T. Liu, B. Hui, M. Fu, S. Hou, B. Luo and G. Wang, "Experimental and Simulation Analysis of Electrical Breakdown for $220 \mathrm{kV}$ Silicone Rubber Pre-moulded Cable Joints," IEEE Int. Electr. Insul. Conf. (INSUCON), 2017.
[3] E. Kantar, D. Panagiotopoulos and E. Ildstad, "Factors Influencing The Tangential AC Breakdown Strength of Solid-Solid Interfaces," IEEE Trans. on Dielectr. Electr. Insul., vol. 23, no. 3, pp. 1778-1788, 2016.

[4] B. X. Du, J. G. Su, Jin Li and Tao Han, "Effect of Mechanical Stress on Treeing growth Characteristics in HTV Silicone Rubber," IEEE Trans. on Dielectr. Electr. Insul., vol.24, no.3, pp.1547-1556, 2017.

[5] "Mechanical Effects on Extruded Dielectric Cables and Joints Installed in Underground Transmission Systems in North America," EPRI, Palo Alto, CA:, 1001849, 2004.

[6] S. Lee, Y. Kim, I. Lee and N. Amyot, "Influence of Internal Residual Mechanical Stresses on Local Dielectric Strength of EHV Extruded XLPE Cables," IEEE Electr. Insul. Conf. Electr. Manu. Coil. Winding Conf., 2001.

[7] N. Amyot, E. David, S. Y. Lee and I. H. Lee, "Influence of Post Manufacturing Residual Mechanical Stress and Crosslinking Byproducts on Dielectric Strength of HV Extruded Cables," IEEE Trans. on Dielectr. Electr. Insul., vol.9, pp. 458-466, 2002.

[8] A. Toya, M. Shimazu, S. Umeda and S. Nishikawa, "Recent Technologies of Joints for HV and EHV XLPE Cables in Japan," IEEJ Trans. Electr. Electron. Eng., vol. 2, pp. 523-530, 2007.

[9] J. Cardinaels, P. Heuillet and P. Meyer, "Study of the Viscoelastic Behaviour of Cold-shrinkable Joints for MV Cables, IEEE Transmission and Distribution Conf. 1999.

[10] C. P. Martin, A. S. Vaughan and S. J. Sutton, "The Thermomechanical Behaviour of Crosslinked Polyethylene Cable Insulation Material," Annu. Rep. Conf. Electr. Insul. Dielectr. Phenom. (CEIDP), 2003.

[11] N. Amyot and E. David, "A Study of Interfacial Pressure Behavior for Two Types of Thermally Cycled Coldshrikable Joints," IEEE Int. Symp. Electr. Insul. (ISEI), 2002, pp. 476-480.

[12] H. Takei, K. Mochizuki, K. Yokosuka, K. Takahashi, I. Takaoka, T. Tashiro, H. Kawahara and Y. Hane, "Development of Cold-shrinkable Straight-Through Joints for $22 \mathrm{kV}$ XLPE Cables," Furukawa Review, no. $19,2000$.

[13] A. N. Gent, Engineering with Rubber, $3^{\text {rd }}$ edition, Hanser, Munich, 2012.

[14] C. Li and H. Qin, "A Study of the interfacial Pressure in Cable Joint Based on Finite Element Method," Advanced Materials Research. 2014.

[15] C. D. Hooper and G. Marshall, "Low Temperature Elastic Behavior of Fourteen Computed Elastomers," Materials Division Propulsion and Vehicle Engineering Laboratory, NASA Technical Memorandum, 1964.

[16] X. Qi and S. Boggs, "Thermal and Mechanical Properties of EPR and XLPE Cable Compounds," IEEE Electr. Insul. Mag., vol. 22, pp.19-24, 2006.

[17] J. Seng, "Inverse Modelling of Material Parameters for Rubber like Materials: Create a New Methodology of Predicting the Material Parameters Using Indentation Bending Test," $\mathrm{PhD}$ dissertation, Liverpool John Moore's University, 2015.

[18] M. Shahzada, A. Kamranb, M. Z. Siddiquia and M. Farhana, "Mechanical Characterization and FE Modelling of a Hyperelastic Material," Materials Research, vol. 18, no. 5, 2015.

[19] L. Bernardi,R. Hopf, A. Ferrari, A.E. Ehret and E. Mazza, "On the large strain deformation behavior of silicone-based elastomers for biomedical applications," Polymer Testing, vol. 58, pp. 189-198, 2017.

[20] L. Meunier, G. Chagnon, D. Favier, L. Orgeas and P. Vacher, "Mechanical experimental characterisation and numerical modelling of an unfilled silicone rubber," Polymer Testing, vol. 27, pp. 765-777, 2008.

[21] M.H.R. Ghoreishy, M. Firouzbakht and G. Naderi, "Parameter determination and experimental verification of Bergström-Boyce hysteresis model for rubber compounds reinforced by carbon black blends," Materials and Design, vol. 53, pp. 457-465, 2014.

[22] L.A.Gracia, E.Liarte, J.L.Pelegay and B.Calvo, "Finite element simulation of the hysteretic behaviour of an industrial rubber. Application to design of rubber components," Finite Elements in Analysis and Design, vol. 46, pp. 357-368, 2010.

[23] J. R. Davis, Tensile Testing, Second edition, ASM International, Ohio, 2004.

[24] V. Vullo, Circular Cylinders and Pressure vessels Stress: Analysis and design, Springer, 2014. 